\title{
THE PULMONARY DIFFUSING CAPACITY AND VENTILATORY CAPACITY BEFORE AND AFTER MITRAL VALVOTOMY
}

\author{
BY \\ J. M. REID AND J. G. STEVENSON \\ From the Cardio-thoracic Unit, Mearnskirk Hospital, Glasgow
}

Received November 4, 1963

\begin{abstract}
A previous communication (Reid and Stevenson, 1963) reported the pre-operative results of the pulmonary diffusing capacity $\left(\mathrm{D}_{\mathrm{LCO}}\right)$ in 53 patients suffering from mitral valve disease. These were correlated with the pressure in the pulmonary circulation and with the size of the mitral orifice. With progressive severity of the mitral obstruction, the $\mathrm{D}_{\mathrm{LCO}}$ was correspondingly adversely affected.

The purpose of the present paper is to present follow-up studies in those of the 53 patients who were operated on. Though 46 underwent mitral valvotomy, further studies have been carried out in only 36 ( 3 deaths have occurred, 1 in the early post-operative period, 2 later from congestive cardiac failure); 7 have defaulted, failing to return for repeat studies. However, an additional 4 have been studied both before and after valvotomy, so that a total of 40 patients is available for analysis. Pressures were recorded routinely at operation in left ventricle, left atrium, and pulmonary artery, both before and after valvotomy. Repeat lung function studies were carried out six to nine months after operation, to allow the circulation to become readjusted following satisfactory relief of the obstruction at the mitral valve.
\end{abstract}

\section{RESULTS}

In 5 of the 40 patients under discussion, pressure in the pulmonary circulation before valvotomy was normal. Significant pulmonary hypertension was present in the remaining 35 , the systolic pressure being in the range $31-60 \mathrm{~mm}$. $\mathrm{Hg}$ in 16 and $61-100 \mathrm{~mm}$. $\mathrm{Hg}$ in 19 . All but 3 showed a substantial fall immediately after valvotomy, though the pressure did not necessarily revert to the normal range in every case. In the three referred to, cardiac catheterization was repeated six to nine months after the operation; the results are given in Table $I$.

A significant reduction in pulmonary artery pressure is now apparent in all three but in none has it fallen to normal. The $\mathrm{D}_{\mathrm{LCO}}$, which pre-operatively was low in all three and showed no increase on exercise, has shown no improvement.

In all 40 the pulmonary diffusing capacity was estimated both before and then six to nine months after operation. In addition, tests of ventilatory capacity were performed (for methods see Reid and Stevenson, 1963). In Fig. 1 and 2 the $D_{\text {LCo }}$ is correlated with valve size before and after operation. Those with minimal obstruction of the valve (an orifice of $3 \mathrm{~cm}$. in the longest diameter) showed little encroachment on diffusing capacity before operation, and hence, as anticipated, there was no significant alteration afterwards. Those with severe stenosis (an orifice of $1 \mathrm{~cm}$.) had moderately severe impairment of $\mathrm{D}_{\mathrm{LCO}}$, and while the majority derived both subjective and objective improvement (the latter manifested by a fall in pulmonary artery and left atrial pressures, regression of pulmonary congestion and of mitral configuration of the heart), there was no corresponding improvement in diffusing capacity. 
TABLE I

Cardiac Catheterization before and after Mitral Valvotomy in Three Patients with Mitral Stenosis and PULMONARY HYPERTENSION

\begin{tabular}{c|c|c|c}
\hline $\begin{array}{c}\text { P.A. pressure } \\
\text { before operation } \\
\text { (mm. Hg) }\end{array}$ & $\begin{array}{c}\text { P.A. pressure } \\
\text { 6-9 months after } \\
\text { operation (mm. Hg) }\end{array}$ & $\begin{array}{c}\text { DLco pre- } \\
\text { operatively } \\
\text { (mm./min./mm. Hg) }\end{array}$ & $\begin{array}{c}\text { Dico post- } \\
\text { operatively } \\
\text { (mm./min./mm. Hg) }\end{array}$ \\
\hline $75 / 45$ & $40 / 30$ & $15 / 14$ & $14 / 15$ \\
$90 / 40$ & $70 / 40$ & $12 / 14 \cdot 5$ & $10 / 14$ \\
$70 / 30$ & $50 / 30$ & $9 \cdot 6 / 9 \cdot 4$ & $12 / 14$ \\
\hline
\end{tabular}

In the intermediate category are those with moderate mitral stenosis (valve orifice of 2 or $2.5 \mathrm{~cm}$.). The 16 cases comprising this group had, with few exceptions, near normal $D_{L C o}$ at rest and exercise, but later studies showed no improvement. Some in fact were found to have lower values for $D_{L C O}$ after apparently successful operative relief of their stenosis.

Fig. 3 and 4 correlate $D_{\text {LCO }}$ with pulmonary artery pressure, and again the striking feature is the impairment before operation of diffusing capacity at rest with no rise on exercise in those with severe mitral stenosis and marked pulmonary hypertension, i.e. it is low and fixed. Even after successful valvotomy, with improvement of circulatory hæmodynamics, this advantage is not reflected by any alteration in $\mathrm{D}_{\mathrm{LCO}}$.

The following case illustrated these various aspects.

Case History. A woman of 36 with Grade II dyspnœa and pure mitral stenosis was found at operation to have severe stenosis (valve orifice $1 \mathrm{~cm}$.). Pulmonary artery pressure had measured $85 / 60 \mathrm{~mm}$. $\mathrm{Hg}$, and
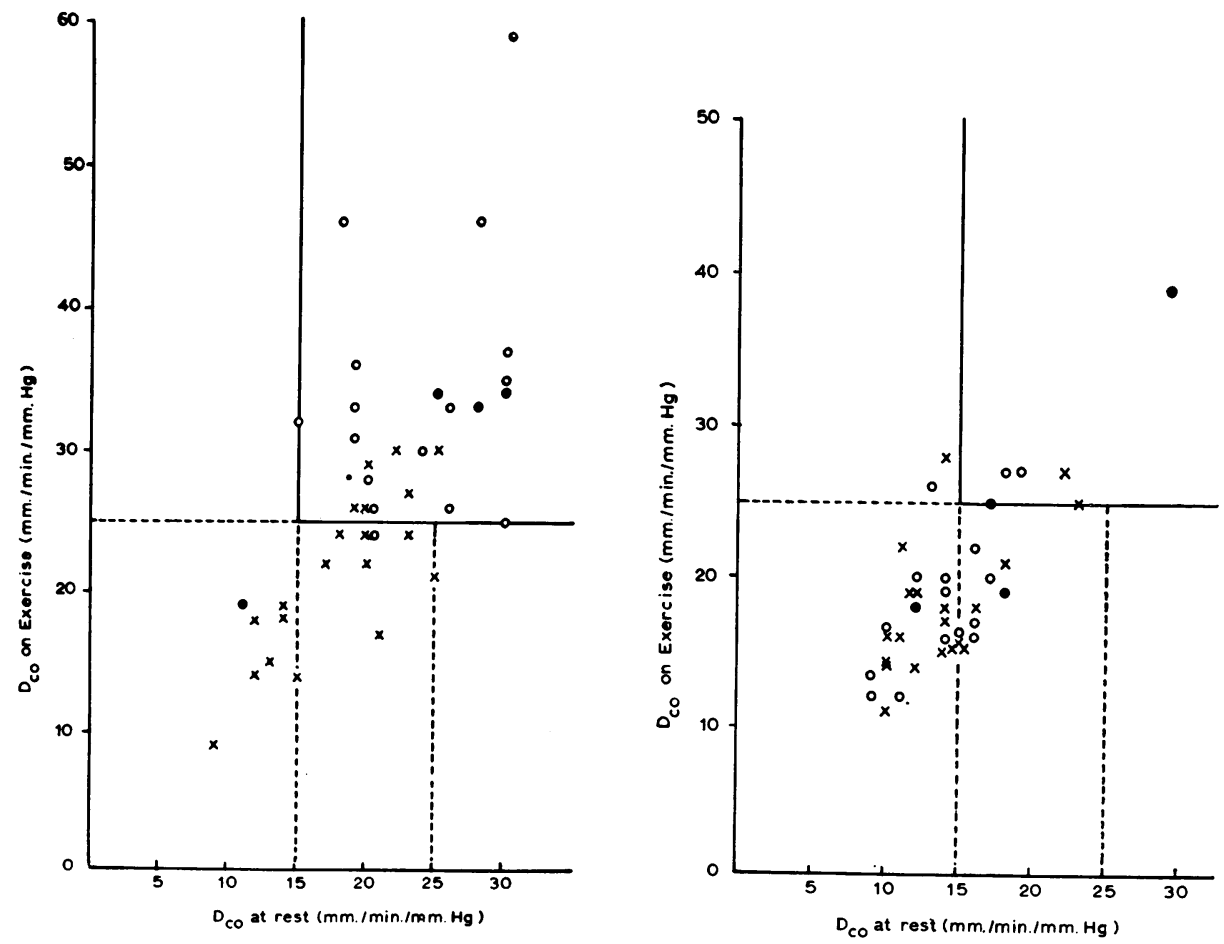

FIG. 1 and 2.-Correlation of $D_{L C O}$ with valve size before and after valvotomy. $(x=1 \cdot 0-1 \cdot 5 \mathrm{~cm}$. (20 patients); $O=2 \cdot 0-2 \cdot 5$ (16 patients); and $\bullet=3.0 \mathrm{~cm}$. 

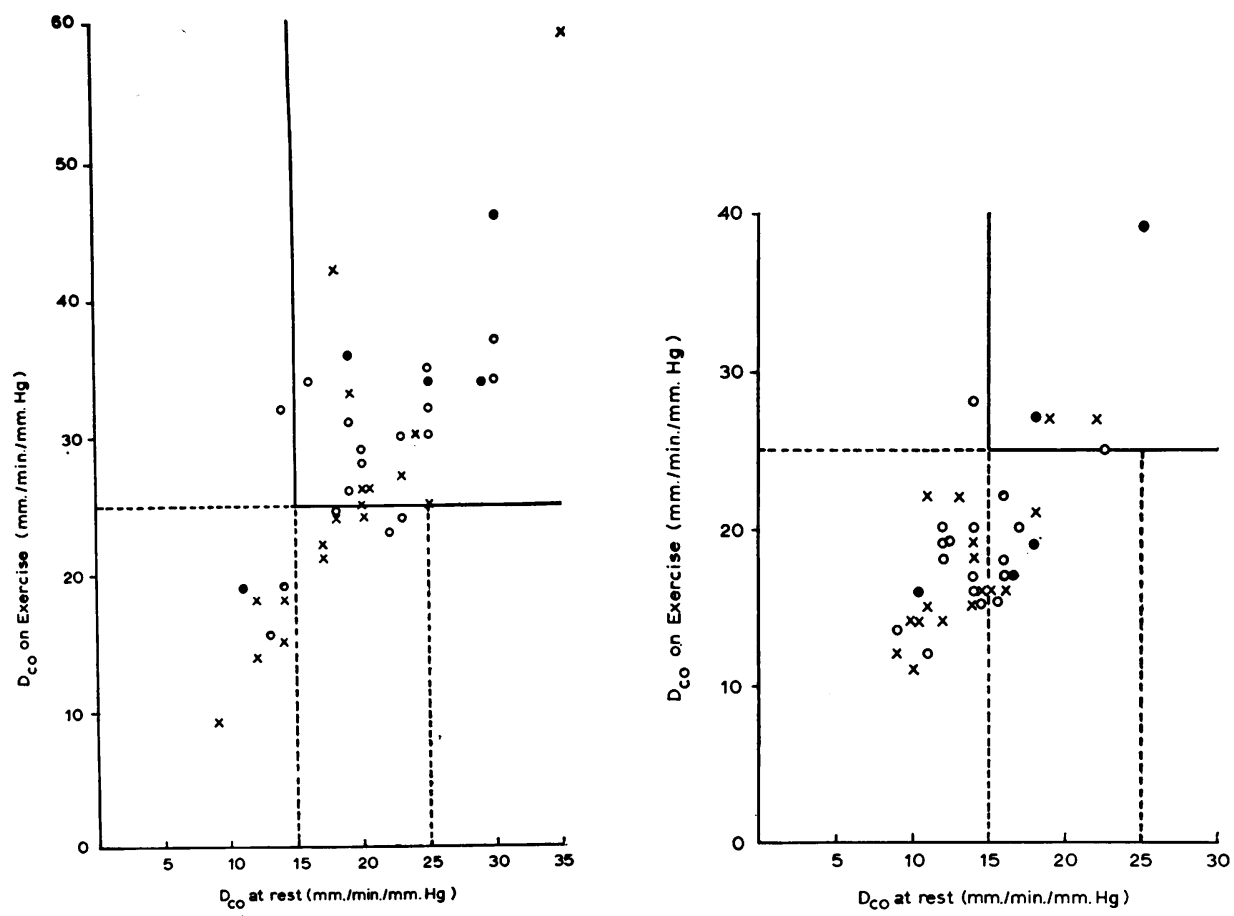

FIG. 3 and 4.-Correlation of DLCo with pulmonary artery pressure before and after valvotomy. $x=$ P.A. pressure of $61 \mathrm{~mm}$. Hg or more (19 patients); $\mathrm{O}=\mathrm{P}$.A. pressure of $31-60 \mathrm{~mm} . \mathrm{Hg}(17$ patients); and $\mathrm{O}=$ P.A. pressure of $15-30 \mathrm{~mm}$. $\mathrm{Hg}$ (5 patients).

after a satisfactory commissurotomy it dropped to $66 / 35 \mathrm{~mm}$. $\mathrm{Hg}$. When seen nine months after valvotomy she was practically symptom free, and radiography showed that the pulmonary conus was no longer prominent; the left atrium had diminished in size, and Kerley's lines (obvious in the pre-operative film) had disappeared (Fig. 5 and 6). The $D_{\mathrm{LCO}}$ before operation was $18 \mathrm{~mm} . / \mathrm{min} . / \mathrm{mm}$. $\mathrm{Hg}$ at rest and $24 \mathrm{~mm} . / \mathrm{min}$./ $\mathrm{mm}$. Hg on exercise, while the present readings are 22 and $27 \mathrm{~mm} . / \mathrm{min} . / \mathrm{mm} . \mathrm{Hg}$, respectively.

Ventilatory Function. In the 20 patients with critical mitral stenosis, the mean vital capacity before operation was $2100 \mathrm{ml}$. and rose to a mean of $2300 \mathrm{ml}$. after operation. The corresponding mean values for the maximum voluntary ventilation (M.V.V.) were 581 . and 621 ., respectively. These figures represent an appreciable impairment of ventilatory function, and the post-operative figures show only slight improvement. However, while some of these 20 showed no alteration in either vital capacity or M.V.V. following valvotomy (indicating permanent lung damage from either concomitant pulmonary emphysema or irreversible pulmonary vascular changes), some showed increases ranging from 7 to as much as 60 per cent.

The remaining 20 with only either mild or moderate obstruction of the mitral valve had mean pre-operative readings for vital capacity and M.V.V. of $2200 \mathrm{ml}$. and 641 . respectively. By contrast, there was a significant rise in each after operation-to means of $2600 \mathrm{ml}$. and $73 \mathrm{1}$., respectively.

Excluding patients who experienced attacks of chest infection which are common in established mitral stenosis and are associated with pulmonary congestion, there were six patients who had clinical and radiological evidence of emphysema in addition to mitral stenosis. Table II summarizes the relevant pre- and post-operative hæmodynamic findings in these six. The mean vital capacity measured $1600 \mathrm{ml}$. before operation, rising to a mean of only $1700 \mathrm{ml}$. after operation. Corresponding mean levels for M.V.V. were 42 and 431 . respectively. 


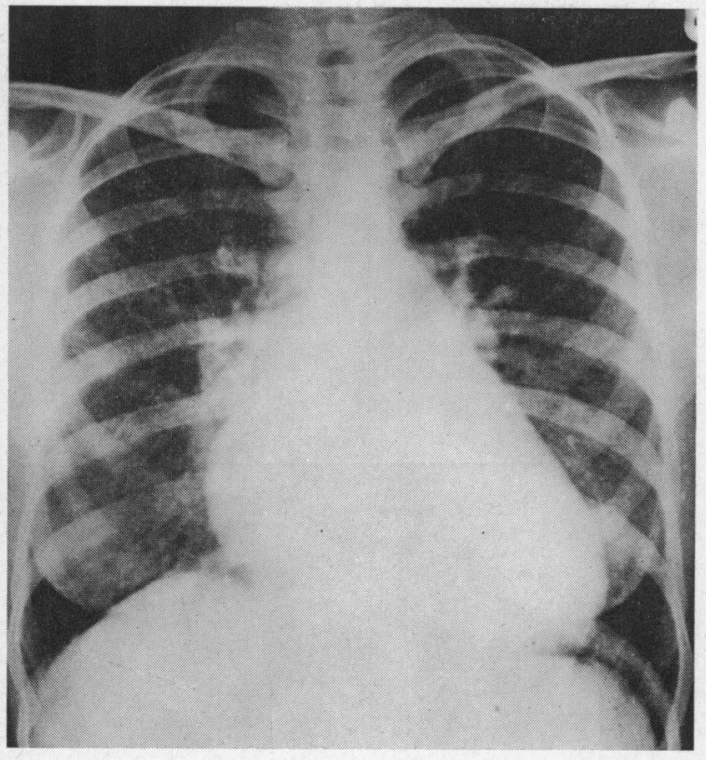

FIG. 5.

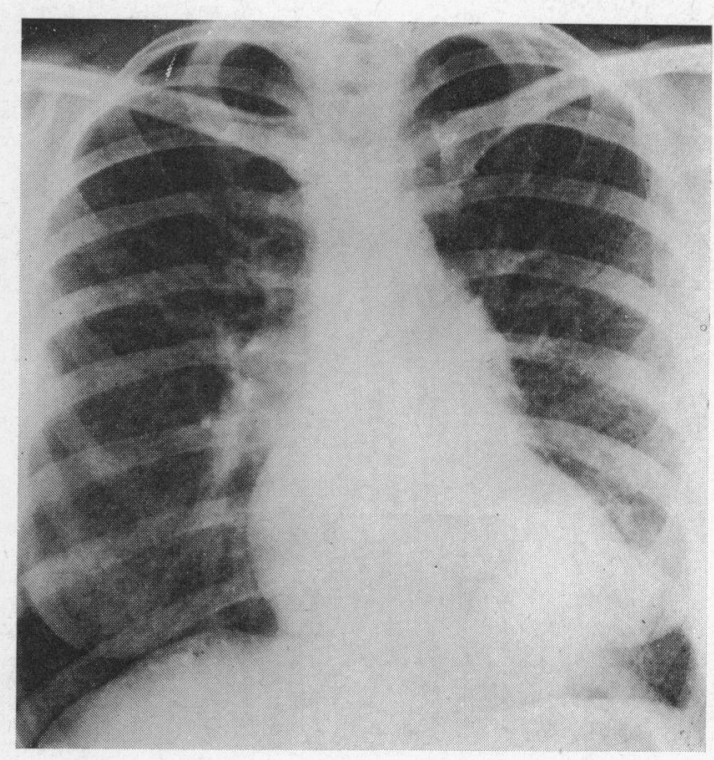

FIG. 6.

FIG. 5 and 6.-Pre- and post-operative chest radiographs of patient with severe mitral stenosis and marked pulmonary hypertension.

TABLE II

Six Patients with Mitral Stenosis and Chronic Bronchitis

\begin{tabular}{|c|c|c|c|c|c|c|c|}
\hline & \multirow{2}{*}{$\begin{array}{c}\text { Vital } \\
\text { capacity } \\
\text { (ml.) }\end{array}$} & \multirow{2}{*}{$\begin{array}{l}\text { M.V.V. } \\
\text { (1./min.) }\end{array}$} & \multirow{2}{*}{$\begin{array}{c}\text { P.A. } \\
\text { pressure } \\
(\mathrm{mm} . \mathrm{Hg})\end{array}$} & \multicolumn{2}{|c|}{$\mathrm{D}_{\mathrm{LCO}}(\mathrm{mm} . / \mathrm{min} . / \mathrm{mm} . \mathrm{Hg})$} & \multirow{2}{*}{$\begin{array}{l}\text { Valve } \\
\text { size } \\
(\mathrm{cm} .)\end{array}$} & \multirow{2}{*}{$\begin{array}{l}\text { Present } \\
\text { condition }\end{array}$} \\
\hline & & & & Rest & Exercise & & \\
\hline $\begin{array}{l}\text { Before } \\
\text { After }\end{array}$ & $\begin{array}{l}1500 \\
2400\end{array}$ & $\begin{array}{l}45 \\
65\end{array}$ & $\begin{array}{l}75 \\
35\end{array}$ & $\begin{array}{l}20 \\
15\end{array}$ & $\begin{array}{l}24 \\
16\end{array}$ & 1 & Improved \\
\hline $\begin{array}{l}\text { Before } \\
\text { After }\end{array}$ & $\begin{array}{l}1400 \\
1700\end{array}$ & $\begin{array}{l}40 \\
35\end{array}$ & $\begin{array}{l}80 \\
35\end{array}$ & $\begin{array}{r}11 \\
8\end{array}$ & $\begin{array}{l}19 \\
17\end{array}$ & 1 & $\begin{array}{l}\text { Very slight } \\
\text { improvement }\end{array}$ \\
\hline $\begin{array}{l}\text { Before } \\
\text { After }\end{array}$ & $\begin{array}{l}1800 \\
1500\end{array}$ & $\begin{array}{l}52 \\
45\end{array}$ & $\begin{array}{l}60 \\
40\end{array}$ & $\begin{array}{r}18 \\
9\end{array}$ & $\begin{array}{l}30 \\
13\end{array}$ & $2 \cdot 5$ & Unchanged \\
\hline $\begin{array}{l}\text { Before } \\
\text { After }\end{array}$ & $\begin{array}{l}2000 \\
1600\end{array}$ & $\begin{array}{l}40 \\
35\end{array}$ & $\begin{array}{l}75 \\
40\end{array}$ & $\begin{array}{l}15 \\
14\end{array}$ & $\begin{array}{l}14 \\
15\end{array}$ & $1 \cdot 5$ & Improved \\
\hline $\begin{array}{l}\text { Before } \\
\text { After }\end{array}$ & $\begin{array}{l}1500 \\
1500\end{array}$ & $\begin{array}{l}37 \\
40\end{array}$ & $\begin{array}{l}70 \\
45\end{array}$ & $\begin{array}{l}13 \cdot 6 \\
15\end{array}$ & $\begin{array}{l}15 \cdot 9 \\
16\end{array}$ & $1 \cdot 5$ & $\begin{array}{l}\text { Slight } \\
\text { improvement }\end{array}$ \\
\hline $\begin{array}{l}\text { Before } \\
\text { After }\end{array}$ & $\begin{array}{l}1500 \\
1600\end{array}$ & $\begin{array}{l}40 \\
40\end{array}$ & $\begin{array}{l}70 \\
50\end{array}$ & 12 & $14^{9 \cdot 4}$ & 1 & Improved \\
\hline
\end{tabular}

\section{Discussion}

While several pre-operative studies of $\mathrm{D}_{\mathrm{LCo}}$ have been recorded in patients with mitral stenosis (Carroll, Cohn, and Riley, 1953; McIlroy and Apthorp, 1958; Auchincloss, Gilbert, and Eich, 1959) there are few reports comparing pre- and post-operative assessment (Arnott, 1963). Of the 40 patients under review, 5 had no pulmonary hypertension and obstruction of the mitral valve was not severe. In them, both ventilatory and diffusing capacities were normal before valvotomy, and little alteration occurred when the tests were repeated. 
Disappointingly, those with pulmonary hypertension, in whom there was depleted ventilation and $\mathrm{D}_{\mathrm{LCO}}$ before operation, showed little corresponding improvement in $\mathrm{D}_{\mathrm{LCO}}$ after operation, though in the majority the pulmonary artery pressure fell and ventilation showed a slight increase. Of these 35, 6 had concomitant bronchitis with emphysema, and it is conceivable that the structural changes in both the lung alveoli and pulmonary vascular bed produced by the latter could account for failure of the $D_{L C O}$ to increase.

Hayward (1955) demonstrated that though pulmonary œdema was commonly an early feature of severe mitral obstruction, it became less prominent with the passage of time. This he attributed to the fact that a physical barrier gradually developed between the capillaries and alveoli, due to a combination of compensatory thickening of the capillary wall, interstitial œdema, and hypertrophy of the alveolar basement membrane. These changes would now prevent the passage of fluid into the alveoli, and would explain the rarity of pulmonary ædema in the later stages. Wood (1956) supported this postulate. Once these structural changes in the lung parenchyma have occurred, one would scarcely expect them to reverse even following satisfactory relief of the primary pathological lesion, namely mitral valve obstruction. This explanation could readily account for the failure of $D_{\text {LCo }}$ to show any significant improvement even after successful valvotomy in the cases in this series with severe mitral stenosis.

Wood (1958) classified pulmonary hypertension in general into passive, obstructive, hyperkinetic, and vasoconstrictive. In mitral stenosis pulmonary hypertension is initially passive, in response to a raised left atrial pressure from mitral valve obstruction. Later the factor of vasoconstriction is superimposed, and obliterative, irreversible changes ensue in the pulmonary vasculature. Evans and Short (1957) reported the histological findings in 24 patients with mitral stenosis and pulmonary hypertension. The salient and conspicuous finding was intimal proliferation of muscular arteries, with reduction in the pulmonary arterial bed. Moreover, total obliteration of segmental arteries, in addition to areas of thrombosis and infarction, produced structural and permanent lung changes.

Uneven capillary blood flow, the result of focal thrombosis or embolism of pulmonary arterioles, or of pulmonary congestion, will lead to uneven ventilation-perfusion relationships (Comroe et al., 1962 ; and Arnott, 1963) and in turn will affect $D_{L C O}$. Many of these factors are operative in cases of established mitral stenosis, and either alone or in combination can adversely influence the facility with which gaseous diffusion can occur.

McIlroy and Apthorp (1958) contended that pulmonary hypertension per se had little effect on pulmonary function, but changes associated with the raised pressure or arising secondary to it could have a profound influence.

Finally, one must make allusion to the possible adverse effect of thoracotomy on lung function. Following mitral valvotomy, many patients have a small hæmorrhagic pleural effusion at the base of the left lung. While this is rapidly absorbed, it may well produce pleural thickening which can eventually impair the function of the underlying lung.

Ventilatory function was found to be considerably reduced in patients with moderate to severe mitral valve obstruction. Significant improvement followed in the majority after surgical relief of their stenosis, this increase paradoxically being most obvious in those with moderate stenosis. Arnott (1963) found that the most noticeable recordable change towards normality after valvotomy was that of ventilation. This was manifested by an increase in M.V.V. and a reduction in minute ventilation during exercise.

Aber (1963) studied 84 patients with mitral stenosis in an attempt to single out those with true bronchitis as distinct from simple pulmonary congestion. The latter group he found to have little in the way of airway obstruction, whereas the genuine bronchitics (38 out of the 84) had evidence of this in the way of increased residual volume, decreased M.V.V., and inefficient intrapulmonary alveolar mixing. Six of the 40 patients under discussion in the present paper had a mean vital capacity of 1600 and M.V.V. of 421 ,, respectively, as compared with respective mean values of 2100 and 601 . for the other 34. Furthermore, the F.E.V. (1 second) measured 60 per cent or less 
in these 6, as against a predicted level of 87 per cent. These 6 had a background of recurrent bronchitis and radiological evidence of emphysema, and no significant improvement in lung function tests was recorded following operation.

Harris and Heath (1962) reported variable results in diffusing capacity in mitral stenosis. Grouping the $D_{L C O}$ into its two components, that of the alveolar capillary membrane $\left(D_{M}\right)$ and the volume of blood in the pulmonary capillaries $\left(V_{C}\right)$, the diffusing capacity will depend ultimately on the interplay of these two. The volume of blood in the pulmonary capillaries is increased in mitral stenosis and this, with dilatation of the capillaries, will tend to increase the surface area available for respiratory gaseous exchange. Conversely, œdema and fibrosis of the alveolar membrane will provide a strong barrier to diffusion. The over-all effect thus is for $D_{\text {Lco }}$ to be impaired in mitral stenosis. Manifestly, if the structural changes in the alveolar membrane fail to revert following valvotomy, little improvement can be anticipated in the $\mathrm{D}_{\mathrm{LCO}}$.

\section{SUMMARY}

Pre- and post-operative studies in 40 patients with mitral stenosis have been presented. All underwent mitral valvotomy, and pulmonary function has been correlated with the pressure in the pulmonary circulation and the size of the mitral orifice as determined at operation.

In early cases and those with minimal obstruction of the mitral valve (as exemplified by the absence of significant pulmonary hypertension and a mitral orifice measuring $2.5 \mathrm{~cm}$. or more in its longest diameter) tests of both ventilation and diffusion capacities were virtually normal before valvotomy and were almost identical afterwards.

In more severe obstruction, particularly in the presence of pulmonary hypertension, $\mathrm{D}_{\mathrm{LCO}}$ was impaired before operation, while ventilatory function was encroached upon. Reasons for these effects such as pulmonary congestion and narrowing of pulmonary capillary bed are put forward. While the majority had both objective and subjective improvement after operation, there was little change in either ventilation or diffusion. It is postulated that the principal reason is irreversible lung damage, not only from pulmonary endarteritis but due to thickening of the alveolar membrane. An additional factor is possibly pleural thickening, the consequence of thoracotomy.

The authors wish to acknowledge the assistance of Mr. R. S. Barclay, Consultant Thoracic Surgeon, who operated on all the patients. They are also indebted to Dr. I. Anderson and to his Biochemistry staff, and to the various physicians who referred their cases for mitral valvotomy.

\section{REFERENCES}

Aber, C. P. (1963). 'Bronchitis' in patients with mitral stenosis. Thorax, 18, 50.

Arnott, W. M. (1963). The lungs in mitral stenosis. Brit. med. J., 2, 823.

Auchincloss, J. H., Jr., Gilbert, R., and Eich, R. H. (1959). The pulmonary diffusing capacity in congenital and rheumatic heart disease. Circulation, 19, 232.

Carroll, D., Cohn, J. E., and Riley, R. L. (1953). Pulmonary function in mitral valvular disease. Distribution and diffusion characteristics in resting patients. J. clin. Invest., 32, 510.

Comroe, J. H., Forster, R. E., Dubois, A. B., Briscoe, W. A., and Carlsen, E. (1962). The Lung, 2nd ed. Year Book Medical Publishers, Chicago.

Evans, W., and Short, D. S. (1957). Pulmonary hypertension in mitral stenosis. Brit. Heart J., $19,457$.

Harris, P., and Heath, D. (1962). The Human Pulmonary Circulation, p. 234 . Livingstone, Edinburgh and London.

Hayward, G. W. (1955). Pulmonary œdema. Brit. med. J., 1, 1361. Mcllroy, M. B., and Apthorp, G. H. (1958). Pulmonary function in pulmonary hypertension. Brit. Heart J., 20, Reid, J. M., and Stevenson J. G. (1963). Pulmonary diffusing capacity in mitral valve disease. Brit. Heart J., 25,

Wood, P. (1956). Diseases of the Heart and Circulation, 2nd ed., p. 519. Eyre and Spottiswoode, London. 557. 